\title{
A Post-Haustorial Defense Mechanism is Mediated by the Powdery Mildew Resistance Gene, PmG3M, Derived from Wild Emmer Wheat
}

\author{
Zhen-Zhen Wei ${ }^{1,2,+}$, Valentyna Klymiuk ${ }^{1,2,3}{ }^{\oplus}$, Valeria Bocharova ${ }^{1}$, Curtis Pozniak ${ }^{3}(\mathbb{C}$ and \\ Tzion Fahima $1,2, *$ (D) \\ 1 Institute of Evolution, University of Haifa, 199 Abba-Hushi Avenue, Mt. Carmel, 3498838 Haifa, Israel; \\ zhenzhen-wei@hotmail.com (Z.-Z.W.); valentyna.klymiuk@usask.ca (V.K.); bocharovavr@gmail.com (V.B.) \\ 2 The Department of Evolutionary and Environmental Biology, University of Haifa, 199 Abba-Hushi Avenue, \\ Mt. Carmel, 3498838 Haifa, Israel \\ 3 Crop Development Centre and Department of Plant Sciences, University of Saskatchewan, 51 Campus Drive, \\ Saskatoon, SK S7N 5A8, Canada; curtis.pozniak@usask.ca \\ * Correspondence: tfahima@evo.haifa.ac.il \\ + Present affiliation: Department of Agronomy, the Key Laboratory of Crop Germplasm Resource of Zhejiang \\ Province, Zhejiang University, Hangzhou 310058, Zhejiang, China.
}

Received: 4 May 2020; Accepted: 26 May 2020; Published: 28 May 2020

\begin{abstract}
The destructive wheat powdery mildew disease is caused by the fungal pathogen Blumeria graminis f. sp. tritici (Bgt). PmG3M, derived from wild emmer wheat Triticum dicoccoides accession G305-3M, is a major gene providing a wide-spectrum resistance against Bgt. PmG3M was previously mapped to wheat chromosome $6 \mathrm{~B}$ using an $\mathrm{F}_{6}$ recombinant inbred line (RIL) mapping population generated by crossing G305-3M with the susceptible T. durum wheat cultivar Langdon (LDN). In the current study, we aimed to explore the defense mechanisms conferred by PmG3M against $B g t$. Histopathology of fungal development was characterized in artificially inoculated leaves of G305-3M, LDN, and homozygous RILs using fluorescence and light microscopy. G305-3M exhibited $\mathrm{H}_{2} \mathrm{O}_{2}$ accumulation typical of a hypersensitive response, which resulted in programmed cell death (PCD) in Bgt-penetrated epidermal cells, while LDN showed well-developed colonies without PCD. In addition, we observed a post-haustorial resistance mechanism that arrested the development of fungal feeding structures and pathogen growth in both G305-3M and resistant RIL, while LDN and a susceptible RIL displayed fully developed digitated haustoria and massive accumulation of fungal biomass. In contrast, both G305-3M and LDN exhibited callose deposition in attempt to prevent fungal invasion, supporting this as a mechanism of a basal defense response not associated with PmG3M resistance mechanism per se. The presented results shed light on the resistance mechanisms conferred by $P m G 3 M$ against wheat powdery mildew.
\end{abstract}

Keywords: powdery mildew; wild emmer wheat; $P m G 3 M$; post-haustorial resistance; $\mathrm{H}_{2} \mathrm{O}_{2}$ accumulation; programmed cell death

\section{Introduction}

Powdery mildew diseases of plants are widespread in temperate climates and are a continuous threat to agriculture as they evolve quickly to overcome plant resistance [1]. More than 650 species of powdery mildew fungi that can infect over 10,000 plant species were identified [2]. These plant pathogens are obligate biotrophs that can infect leaves, stems, flowers and fruits and frequently decrease the grain yield and quality of agricultural crops [1,3,4]. Blumeria graminis is a filamentous ascomycete parasite fungus infecting Poaceae species including cereal crops, such as wheat (Triticum aestivum) and 
barley (Hordeum vulgare) [4]. B. graminis f. sp. tritici (Bgt) is specific to wheat, while B. graminis f. sp. hordei $(B g h)$ is specific to barley, but their disease cycles are highly similar $[5,6]$. The infection process of the disease, during the asexual stage, includes the following steps and processes: (i) inoculation a haploid conidium of $B g t$ is landing on leaf of a susceptible wheat plant; (ii) germination - the spore is germinating and forming first primary germ tube(s) that would never fully penetrate into epidermal cells, and then a secondary germ tube that will differentiate into an appressorial germ tube (AGT); (iii) penetration-AGT differentiates into a mature appressorium with a narrow protrusion called penetration peg, which directly penetrate the cell walls of host epidermis by means of turgor pressure and enzymatic activity; (iv) colonization the penetration peg is enlarged into a feeding structure called haustorium, formed within the host cell to absorb host nutrients and deliver effector proteins; (v) invasion - secondary hypha outgrowths are produced and generate penetration pegs that infect additional host cells; (vi) dissemination - following the invasion of powdery mildew, circular colonies with elongated and repeatedly branched hyphae are formed and spread epiphytically on the leaf surface. These colonies produce conidiophores that carry chains of conidia that are released to the environment to start new cycles of infection on the same or other plants. Young hyphae are transparent or whitish, while mature colonies are gray-brown color, sometimes showing dark dots that represent the cleistothecia fruiting bodies $[5,6]$.

Plants protect themselves against pathogens by using a variety of chemical and physical defenses. For example, cell wall thickenings called papillae that are formed by deposition of callose, a $(1,3)-\beta$-glucan polymer, accumulated at the site of pathogen penetration, are effective physical barriers to slow pathogen invasion during plant-pathogen interactions [7]. In the early stage of defense responses induced by biotrophs, massive reactive oxygen species (ROS) accumulation can trigger a localized hypersensitive response (HR), a form of programmed cell death, which results in the limitation or even blocking of penetration and development of pathogen colonies, thus resulting in resistance to powdery mildew (reviewed by Hückelhoven [8]). The accumulation of $\mathrm{H}_{2} \mathrm{O}_{2}$ in the epidermal cells was demonstrated to play an important role in defense response of resistant host plants to fungal penetration in different plant-pathogen pathosystems, including wheat- $B g t$ [9].

$P m G 3 M$ is a major resistance gene, derived from wild emmer wheat (WEW) T. dicoccoides accession G305-3M, that was shown to confer resistance to 54 Bgt isolates collected from different wheat species (e.g., T. dicoccoides, T. durum and T. estivum) in various countries representing four continents around the globe [10-12]. PmG3M was genetically mapped to the distal part of wheat chromosome arm 6BL using a mapping population generated from the cross of WEW G305-3M, the donor line of PmG3M, with the Bgt susceptible T. durum cv. LDN [12]. PmG3M was assigned to a chromosome region where no other $P m$ genes were localized in wheat before $[12,13]$, suggesting it as a novel resistance gene, not found previously in the domesticated wheat germplasm. However, the resistance mechanism conferred by $P m G 3 M$ is still unknown.

In the current study, we aimed to explore the defense mechanisms involved in the PmG3M-mediated resistance of wheat against Bgt. We focused on the characterization of fungal growth and development on susceptible versus resistant host in order to dissect the defense mechanism conferred by PmG3M from mechanisms of basal defense responses. We used advanced microscopy imaging technologies to characterize the compatible (susceptible) versus incompatible (resistant) host-parasite interactions at the cellular level of the wheat-Bgt pathosystem. We found that a post-haustorial resistance mechanism was activated by $P m G 3 M$, leading to arrest of the development of fungal feeding structures and termination of growth of the fungal biomass on the leaf surface. Programed cell death was also activated during the defense response of the host plant conferring the PmG3M gene, as evident by the accumulation of $\mathrm{H}_{2} \mathrm{O}_{2}$ in the $\mathrm{Bgt}$ penetrated epidermal cells of the resistant plants. On the other hand, callose deposition most likely represents a basal defense response, since it was detected in both, resistant and susceptible, wheat lines. 


\section{Results}

\subsection{Selection of Plant Material for Histological Studies and Verification of the Inheritance Pattern of the} PmG3M Locus

In the current study, we have characterized the histological defense responses against Bgt in the parental lines G305-3M (resistant, IT = 0) and LDN (susceptible, IT = 4) (Figure 1a) and their $\mathrm{F}_{6}$ RIL progenies (CHR32 and CHR36), previously used for genetic mapping of PmG3M. The selected RILs carry reciprocal-like recombination events between markers stm583 and edm49 that flank the PmG3M locus (Supplementary Tables S1 and S2) and therefore they represent alternative parental alleles along this 6BL chromosome interval.

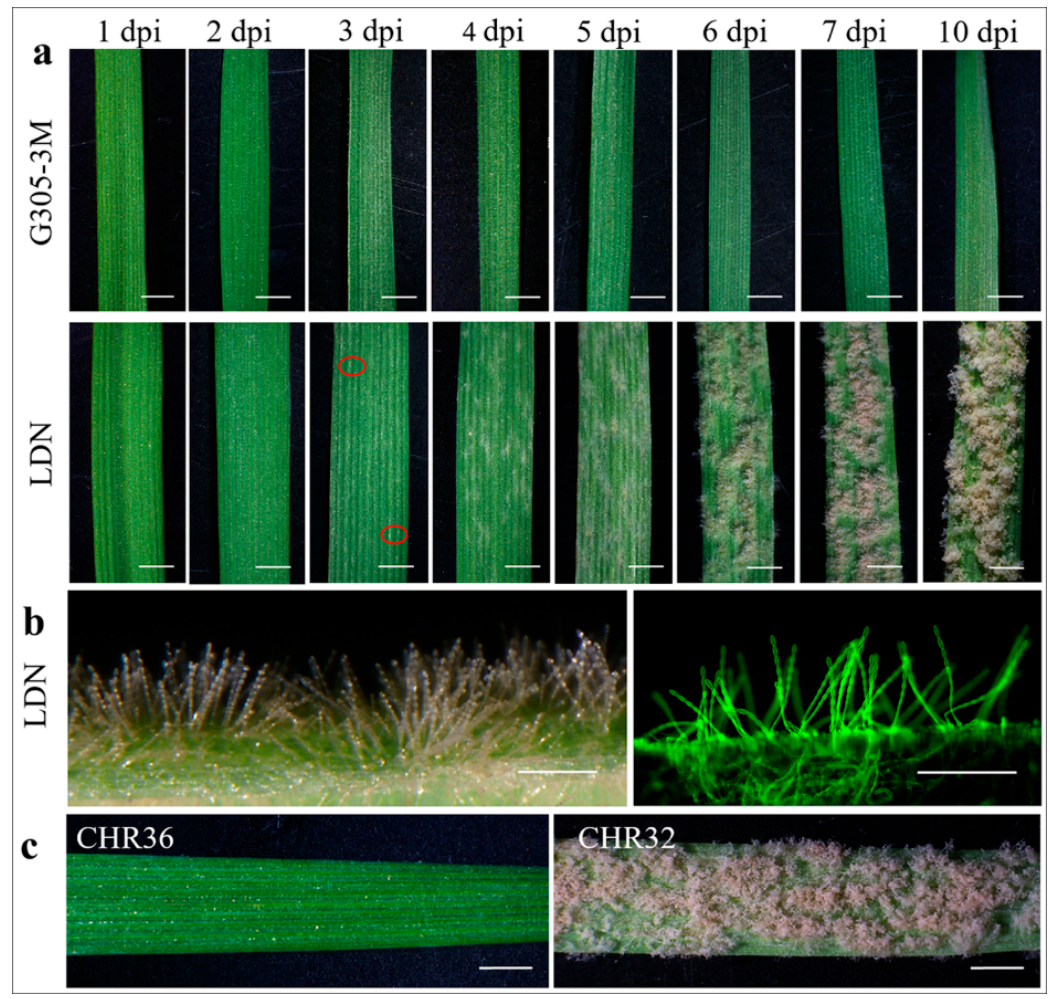

Figure 1. Macroscopic and microscopic observations of the resistant and susceptible host plants at different time points after Bgt\#70 inoculation. (a) Macroscopic observations of G305-3M and LDN at eight time points after $B g t \# 70$ inoculation. The first colonies of $B g t$ are marked with a red circle at $3 \mathrm{dpi}$ on LDN; (b) colony observation on LDN at 5 dpi after Bgt\#70 infection. The Bgt colony on the left side was observed under light microscopy, while the colony on the right was observed under fluorescence microscopy after staining with wheat germ agglutinin (WGA); (c) macroscopic observations of the resistant RIL CHR36 and susceptible RIL CHR32 at 10 dpi. Scale bars: (a,c) 2 mm; (b) $250 \mu \mathrm{m}$.

Furthermore, Bgt test showed that CHR36 is highly resistant (IT $=0$, Figure 1c) to powdery mildew, while CHR32 is susceptible (IT = 4; Figure 1c), indicating that the reciprocal-like recombination events occurred between PmG3M and stm583. To verify the inheritance pattern of the PmG3M locus, we have tested $265 \mathrm{~F}_{2}$ plants, from the cross between G305-3M and LDN, for resistance to isolate $B g t \# 70$. The segregation ratio of the phenotypic response to $B g t$ in this $F_{2}$ population was 3.34R:1S $(\chi 2=0.5547$, $p=0.4564$; Supplementary Table S3), therefore providing further evidence that the PmG3M resistance is conferred by a single dominant gene, derived from WEW accession G305-3M.

\subsection{Disease Assessment of Wheat Powdery Mildew}

The first signs of Bgt colonization were observed under the microscope on the susceptible LDN at 3 days post inoculation (dpi) and small $B g t$ colonies became visible to the naked eye at 4 dpi 
(Figures $1 \mathrm{a}$ and $2 \mathrm{n}-\mathrm{p}$ ). The disease development progressed rapidly thereafter, and at $7 \mathrm{dpi}$ the plants were heavily infected with massive powdery mildew colonies. Moreover, the mycelium color changed from white to gray-brown at $7 \mathrm{dpi}$. The aerial hyphae could be clearly observed under both light and fluorescence microscopy at $5 \mathrm{dpi}$ (Figure 1a,b). In contrast, the resistant G305-3M leaves remained healthy and green, with a slight reddish discoloration most likely associated with the defense response (Figure 1a). The homozygous resistant $\mathrm{F}_{6}$ RIL CHR36 showed the same response to inoculation with Bgt as G305-3M, while the susceptible RIL CHR32 showed the same disease symptoms as LDN at 10 dpi (Figure 1c).

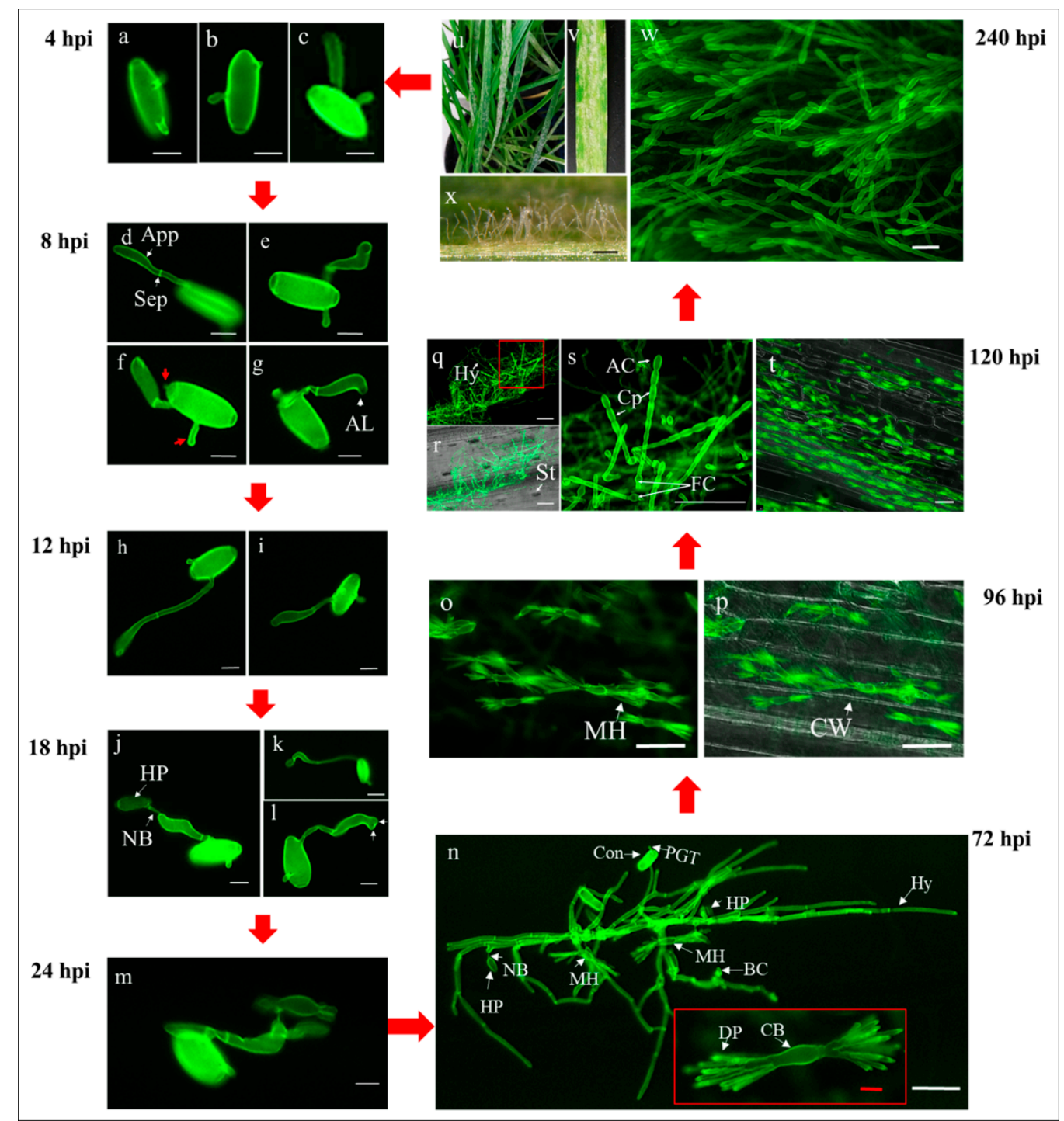

Figure 2. Disease cycle of $B g t \# 70$ on leaf segments of LDN (susceptible parent). All samples were stained with WGA prior to observation under fluorescence microscope; (a-c) germination of Bgt conidia at $4 \mathrm{hpi}$; (d-g) initial stages of appressorial germ tube formation at $8 \mathrm{hpi}$; $(\mathbf{h}, \mathbf{i})$ advanced stages of appressorial germ tubes formation at $12 \mathrm{hpi} ;(\mathbf{j}-\mathbf{l})$ initial stages of penetration and invasion of Bgt into wheat cells at $18 \mathrm{hpi}$; (m) development of mature haustoria at $24 \mathrm{hpi}$; (n) formation of Bgt colonies at $72 \mathrm{dpi}$. A high-resolution close-up image of the mature feeding structure of $B g t$ with central body and digitate processes (finger-like projections) is shown in the red box; $(\mathbf{o}, \mathbf{p})$ feeding structures of $B g t$ at 96 hpi (4 dpi). Bgt haustorium within the invaded plant host cell under fluorescence microscopy (o) and superimposition of fluorescence and bright field images with visible multiple haustoria with multi-digits in individual epidermal cells $(\mathbf{p}) ;(\mathbf{q}-\mathbf{t})$ images of massive colonization and reproduction of Bgt on wheat leaves at $120 \mathrm{hpi}(5 \mathrm{dpi})$ observed under fluorescence microscopy $(\mathbf{q}, \mathbf{s}, \mathbf{t})$ and superimposed 
on a bright field images; (r) colonies with numerous conidiophores and haustoria are shown. The high-resolution close-up image is derived from the red box in $\mathrm{q}$; (u-x) observation of $B g t$ symptoms and conidiophores developed at $240 \mathrm{hpi}(10 \mathrm{dpi})$. Powdery mildew symptoms on intact leaves (u) and leaf segments (v), observation under fluorescence microscopy of Bgt conidiophores, aerial hyphae under light microscopy. AL: apical lobe; App: appressorium; AC: apical conidium; CB: central body; Con: conidium; Cp: conidiophores; CW: cell wall; DP: digitate processes (finger-like projections); BC: bulbous conidiophore; MH: mature haustorium; HP: haustorial primordium; Hy: hyphae; NB: neckband; Sep: septum; St: stomata. Scale bars: (a-m) and (n) red, $10 \mu \mathrm{m} ;(\mathbf{o}-\mathbf{t})$ and (n) white, $50 \mu \mathrm{m}$; (w), $100 \mu \mathrm{m} ;(\mathbf{x}), 250 \mu \mathrm{m}$.

\subsection{Microscopy of Bgt-Wheat Interactions within Infected Leaves}

\subsubsection{Asexual Life Cycle of Bgt on Susceptible LDN Leaf Segments}

In order to characterize the differences between compatible (susceptible) and incompatible (resistant) interactions, the asexual disease cycle of Bgt on leaf segments of LDN seedlings was followed along thirteen successive time points ( $4-240 \mathrm{~h}$ post inoculation (hpi); Figures 2 and 3 ) through fluorescence microscopy observations.

At $4 \mathrm{hpi}$, the germinating conidial spores formed two types of germ tubes, a primary germ tube and a secondary germ tube. The germ tubes were mostly simple, straight, ended with rounded apices and were usually shorter in length than the conidial spores, and their positions relative to the center of conidia were terminal, subterminal or lateral (Figure 2a-c). Moreover, germ tubes emerging from a single conidium did not show a uniform pattern of position and length (Figure 2a-c).

At $8 \mathrm{hpi}$, the elongated secondary germ tubes began to differentiate into swollen appressorial germ tubes, separated by septa. Some of the appressorial germ tubes were longer than the conidia (Figure 2). As shown in Figure 2d-g, the appressoria were not uniform, exhibiting variable shapes and orientation relative to the central axis of the germinating conidia. Several examples are presented here: (i) a concomitantly straight appressorial germ tube and a short primary germ tube at the opposite terminal position (Figure 2d); (ii) a hooked appressorial germ tube and a short primary germ tube at the same terminal position (Figure 2e); (iii) two short primary germ tubes (red arrows) in addition to secondary appressorial germ tubes (Figure 2f). Hooked appressoria with an apical lobe that start to penetrate the epidermal cells can be observed (Figure 2g).

At $12 \mathrm{hpi}$, most of the germinating conidia formed appressoria with typical apical hooks and characteristic septa that separate the differentiated appressoria cells from the conidia (Figure 2h,i). Most of the appressorial germ tubes were longer than the conidia. Within the following six hours, penetration pegs were formed and produced bulb-like haustorial primordia inside the epidermal host cells (Figure 2j-1). Haustorial primordia at the end of the swollen (Figure 2j) and elongated (Figure 2k) appressoria, with primary germ tubes at different positions of the conidium were observed. Elongated and branched appressoria were also observed (Figure 21, branches marked with arrows).

Subsequently, the typical digitate processes (finger-like projections) of haustoria were visible at $24 \mathrm{hpi}$. The formation of secondary hyphae was observed branching from the established appressorium (Figure 2m). At 72 hpi, extensive hyphal growth and repeated penetration from hyphal appressoria resulted in the formation of further digitate haustoria, and establishment of bulbous conidiophores on host epidermal cells (Figure 2n). The mycelial hyphae developed and proliferated on the plant leaf surface at $96 \mathrm{hpi}$ (Figure 1) were accompanied and supported by massive invasion into the epidermal cell layer and formation of numerous haustoria which are feeding the pathogen colonies via multiple digit structures (Figure 2o,p). At this stage, the first batch of conidiophores already began to appear (Figure 3, LDN $96 \mathrm{hpi}$ ) and the first signs of disease can be visualized macroscopically (Figure 1, LDN 4 dpi).

At 120 hpi, massive airborne conidiophores were produced; a surge of haustoria in epidermal cells were accompanied by well-developed colonies (Figure 2q-t). From 120 to 240 hpi there was a sharp increase in sporulation. Colonies were well developed in the susceptible LDN, with many outward 
projections of chains of conidia (Figure $2 \mathrm{u}-\mathrm{w}$ ). Interestingly, the development of hypha was consistent with the direction of the vein extension and the tightly crisscrossed hyphae had close adhesion with the epidermal cells. Moreover, the distribution of haustoria in epidermal cells suggested that hyphae were growing mainly along the vertical direction of the leaves (Figure $2 t$ ). When the young conidia were released from the conidiophores, they initiated a second cycle of inoculation and infection of the host plants, indicating the start of a new disease cycle.

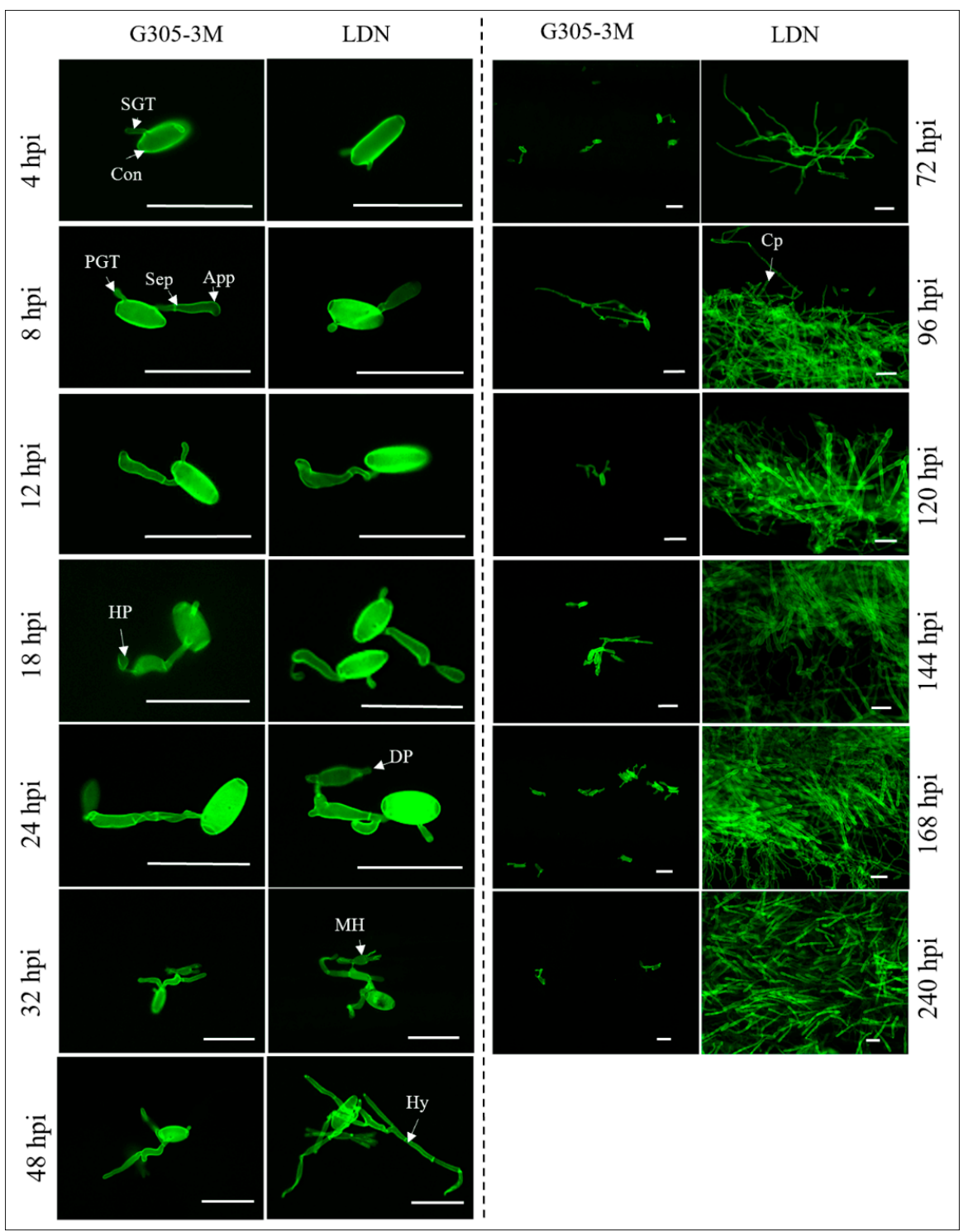

Figure 3. Microscopy of $B g t$-wheat interactions on infected leaves in resistant versus susceptible lines. Segments of G305-3M and LDN leaves were observed under fluorescence microscopy after staining with wheat germ agglutinin (WGA) at 13 time points post inoculation. Scale bar is $50 \mu \mathrm{m}$. App: appressorium; Cp: conidiophore; Con: conidium; DP: digitate processes (finger-like projections); HP: haustorial primordium; Hy: hyphae; MH: mature haustorium; PGT: primary germ tube; Sep: septum; SGT: secondary germ tube.

\subsubsection{Comparison of Fungal Development on Leaves of Susceptible LDN and Resistant G305-3M}

A comparison of fungal development on susceptible LDN and resistant G305-3M young leaves revealed near identical developmental processes during the initial stages of infection, from the point of landing of conidia on the host leaves until the formation of haustorium primordia (0-24 hpi), while striking differences in the extent of $B g t$ development from 32 to 240 hpi were observed for LDN 
(Figure 3). In the LDN leaves, Bgt hyphae were abundant on the leaf surface and penetrated freely the epidermal cells to form mature haustoria within these cells (Figure 3). In contrast, the growth of Bgt on the G305-3M leaves was very limited. Only a few germinated conidia with secondary hyphae could be observed, while the development of most of the germinating conidia was blocked at the haustoria primordium stage (Figure 3).

The resistant RIL CHR36 showed arrest of pathogen development at the haustorial primordia, the same pattern as G305-3M (Supplementary Figure S1, 4 \& 10 dpi), with only a few conidia that developed mature haustoria and secondary hyphae, while the susceptible RIL CHR32 presented the same infection pattern as LDN, with well-developed haustoria at $4 \mathrm{dpi}$, and massive development of conidiophores at $10 \mathrm{dpi}$ (Supplementary Figure S1).

Interestingly, we observed that appressoria of the conidia located near stomata avoided penetrating the stomatal guard cells in both resistant G305-3M and susceptible LDN (Supplementary Figure S2). Even in those cases where spores landed on the stomatal guard cells, the appressoria were extended and avoided guard cell penetration (Supplementary Figures S1b and S2c). Moreover, although multiple mature haustoria formed in one single epidermal cell in LDN at $4 \mathrm{dpi}$, no mature haustoria were observed in stomatal guard cells (Supplementary Figure S2d).

\subsubsection{The Early Stages of Bgt-Wheat Incompatible Interaction in Leaves of the Resistant Line G305-3M}

The early stages of $B g t$-wheat interactions were examined in leaves of the resistant line G305-3M (4-240 hpi) using fluorescence microscopy after staining with WGA (Figures 3 and 4).

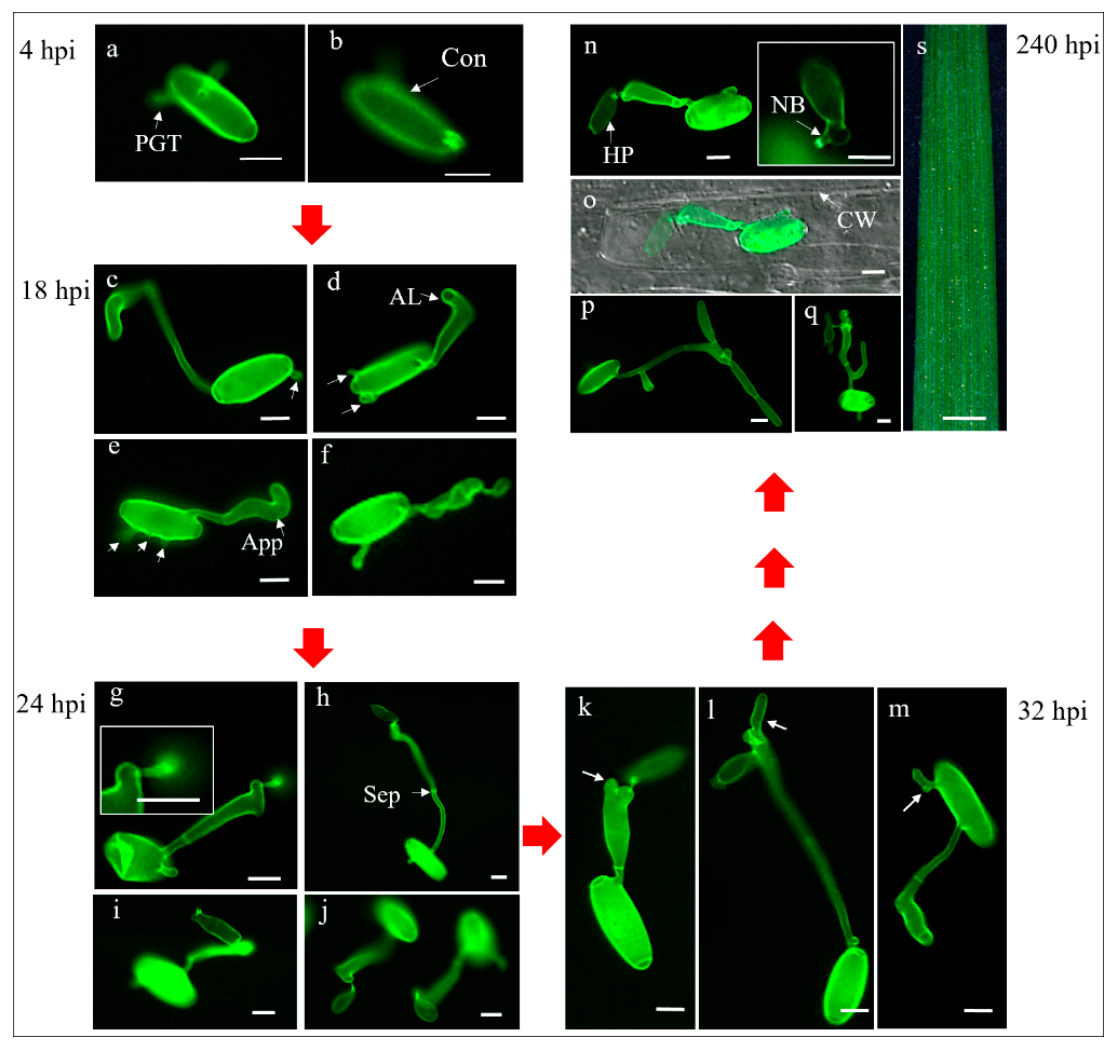

Figure 4. The early stages of $B g t-G 305-3 \mathrm{M}$ incompatible interaction observed after inoculation of resistant leaf segments with isolate $B g t \# 70$. All samples were observed under fluorescence microscopy after staining with WGA; $(\mathbf{a}, \mathbf{b})$ germination of Bgt conidia at $4 \mathrm{hpi} ;(\mathbf{c}-\mathbf{f})$ early stages of penetration into host cells at 18 hpi. Arrest of penetration of Bgt into host cells at $24 \mathrm{hpi}(\mathbf{g}-\mathbf{j})$ and 32 hpi (k-m); (n,o,s) arrest of development of $B g t$ feeding structures within host cells at $240 \mathrm{hpi} ;(\mathbf{p}, \mathbf{q})$ the development of $B g t$ within host cells at 240 hpi. Scale bar is $10 \mu \mathrm{m}$ in (a-q), $1 \mathrm{~mm}$ in (s). AL: apical lobe; App: appressorium; Con: conidium; CW: cell wall; HP: haustorial primordium; NB: neckband; Sep: septum. 
The development of primary germ tubes of the germinating Bgt conidia observed at 4-12 hpi showed the same pattern of development on both the resistant G305-3M and the susceptible LDN leaves (Figures 2-4). At 18 hpi the conidia germinating on G305-3M leaves already produced 1-3 primary germ tubes and fully developed hooked appressoria (Figure 4c, one primary germ tube; $d$, two; e, three; marked with white arrows). In some cases, a premature haustorial primordium was observed extending from the mature appressorium (Figures 3 and $4 \mathrm{f}$ ).

In most cases, haustorial primordia connected to the swollen (Figure 4g) or elongated (Figure 4h) appressoria via neckbands could be observed at $24 \mathrm{hpi}$. Bulb-like haustorial primordia connected to appressoria via neckbands were very common at this stage (Figure 4j), whereas preliminary formation of digitate processes were observed only in rare cases (Figure 4i). At $32 \mathrm{hpi}$, primary germ tubes with branched appressoria (white arrows) and haustorial primordia were commonly observed (Figure 4k,1), while branched primary germ tubes (white arrow) were observed only in very rare cases (Figure $4 \mathrm{~m}$ ).

From $32 \mathrm{hpi} \mathrm{to} 240 \mathrm{hpi}$, for most conidia, there were no further changes in Bgt haustoria development within the invaded host plant cells, as observed in fluorescent images (Figure $4 \mathrm{n}$ ) superimposed on bright field images (Figure 4o); the development of haustoria in G305-3M were arrested at haustorial primordia stage (Figure $4 \mathrm{n}, \mathrm{o}$ ) and no digitate processes were formed. Nevertheless, in a few cases some conidia were able to form haustoria with digitate processes and relatively short secondary hyphae (Figure 4p,q).

Taken together these results indicate that the resistance gene PmG3M activates a post-haustorial resistance mechanism, which leads to the arrest of the fungal feeding structures and termination of fungal colony growth on the leaf surface probably due to lack of nutrients.

\subsection{The Accumulation of Fungal Biomass within Susceptible (LDN and CHR32) Versus Resistant (G305-3M and CHR36) Wheat Lines after Inoculation with Powdery Mildew}

Fungal biomass was assessed by measurement of amount of chitin present in fungal cell walls, but absent in plant cell walls. Within leaf tissues of susceptible CHR32 and LDN it increased sharply from 4 to $10 \mathrm{dpi}$ and the relative quantification of fungal development and colonization fit a typical standard logistic population growth model (LDN: $p<10^{-10}$; CHR32: $p<10^{-8}$ ) (Figure 5). Moreover, the susceptible CHR32 displayed a significantly higher increase in fungal biomass than LDN at the same time frame (5-10 dpi, Figure 5 and Supplementary Figure S3). In contrast, fungal biomass accumulation in the leaves of the resistant lines G305-3M and CHR36 was very low and did not change significantly over the sampling period (1-10 dpi, Figure 5 and Supplementary Figure S3).

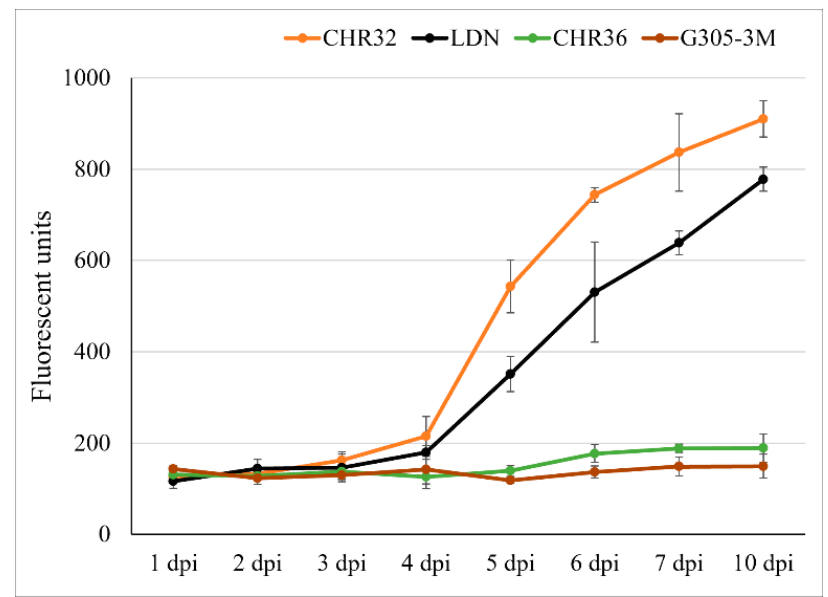

Figure 5. Accumulation of fungal biomass (chitin) within leaf tissues of inoculated wheat lines (LDN and CHR32) susceptible to Bgt, as compared with resistant lines (G305-3M and CHR36) from 1 to 10 dpi after inoculation with Bgt\#70. Error bars denote standard deviation (s.d.) based on five biologic replicates. dpi: days after inoculation. Duncan's multiple range test is described in Supplementary Figure S3. 
A comparison of fungal biomass accumulation between the four tested lines revealed no significant differences between the resistant (G305-3M and CHR36) and susceptible (LDN and CHR32) lines during the first three time points (Figure 5 and Supplementary Figure S3). At $4 \mathrm{dpi}$, significant differences $(p<0.01)$ were observed between the susceptible CHR32 and the resistant lines (G305-3M and CHR36). At the same time point, $\mathrm{LDN}$ had $42.2 \%$ and $26.2 \%$ higher average fungal biomass accumulation compared to CHR36 and G305-3M, but these differences were not significant (Supplementary Figure S3). Significant differences between the resistant and susceptible lines were detected at 5 to $10 \mathrm{dpi}$ (Supplementary Figure S3), at about the time the mycelium became visible under macroscopic observation on CHR32 and LDN (Figure 1). Microscopic examination revealed that during this period, germination of $B g t$ conidia in these two susceptible lines was followed by the elongation and secondary penetration of hyphae and generation of multiple haustoria in epidermal host cells, leading to massive colonization of epidermal cells, as compared to the arrest of fungal development in the resistant lines (Figures 2-4).

\subsection{Epidermal Cell Responses to Bgt Inoculation in Resistant Versus Susceptible Host Plants}

\subsubsection{Callose Deposition in Resistant Versus Susceptible Host Plants after Bgt Inoculation}

The attempts of Bgt hyphae to penetrate into plant cells were often associated with the deposition of wall papillae (Figure 6). In the susceptible LDN, we observed callose at 24 hpi under fluorescence microscopy as an aperture-like halo, with a bright core encasing both the penetration sites of appressorium and primary germ tube. The field of callose deposition that formed under the appressorium penetration site was much larger and brighter than that observed under the penetration site of primary germ tube (Figure 6a). The localization of the oval halos to the attacked epidermal cell beneath the appressorium and primary germ tube was validated by superimposition of fluorescence and bright field microscopy images after aniline blue staining (Figure $6 a, d)$. In the resistant G305-3M, a field of callose deposition can be observed at $24 \mathrm{hpi}$ under the appressorium and a smaller one at the primary germ tube penetration sites (Figure $6 \mathrm{~g}$ ). The localization of the hemispherical papilla with auto fluorescent material directly beneath the Bgt appressorium and a slight papilla formed at the unsuccessful penetration site of primary germ tubes were observed by superimposition of fluorescent and bright field microscopy images after aniline blue staining (Figure 6g,l).

The halo aperture-like callose deposition (white arrow) with a dot-like core in the susceptible LDN with elongated secondary hyphae (orange arrow) was observed at 48 hpi (Figure 6b), while the digitate processes (red arrow) of mature haustorium and papillae (white arrow) at the penetrated site were found under the superimposition of fluorescence and bright field observation (Figure 6e). A bright dot-like callose deposition can be seen at $48 \mathrm{hpi}$ in G305-3M as a response to the attack by primary germ tube, while a patch-like formation of callose deposition emerged beneath the appressorium (Figure $6 \mathrm{~h}, \mathrm{~m}$ ). The localization of the smaller size papilla (white arrow) at the primary germ tube penetration site and a patch-like callose deposition beneath the appressorium was visible under the superimposition of fluorescence and bright field microscopy images (Figure $6 \mathrm{~m}$ ).

At 72 hpi large Bgt colonies were already formed in LDN and many dot-like callose depositions induced by hyphal appressoria were observed beneath them (Figure $6 c, f)$. However, only smaller dot-like callose depositions at the primary germ tube penetration sites were observed in the resistant G305-3M (Figure 6i,n). 


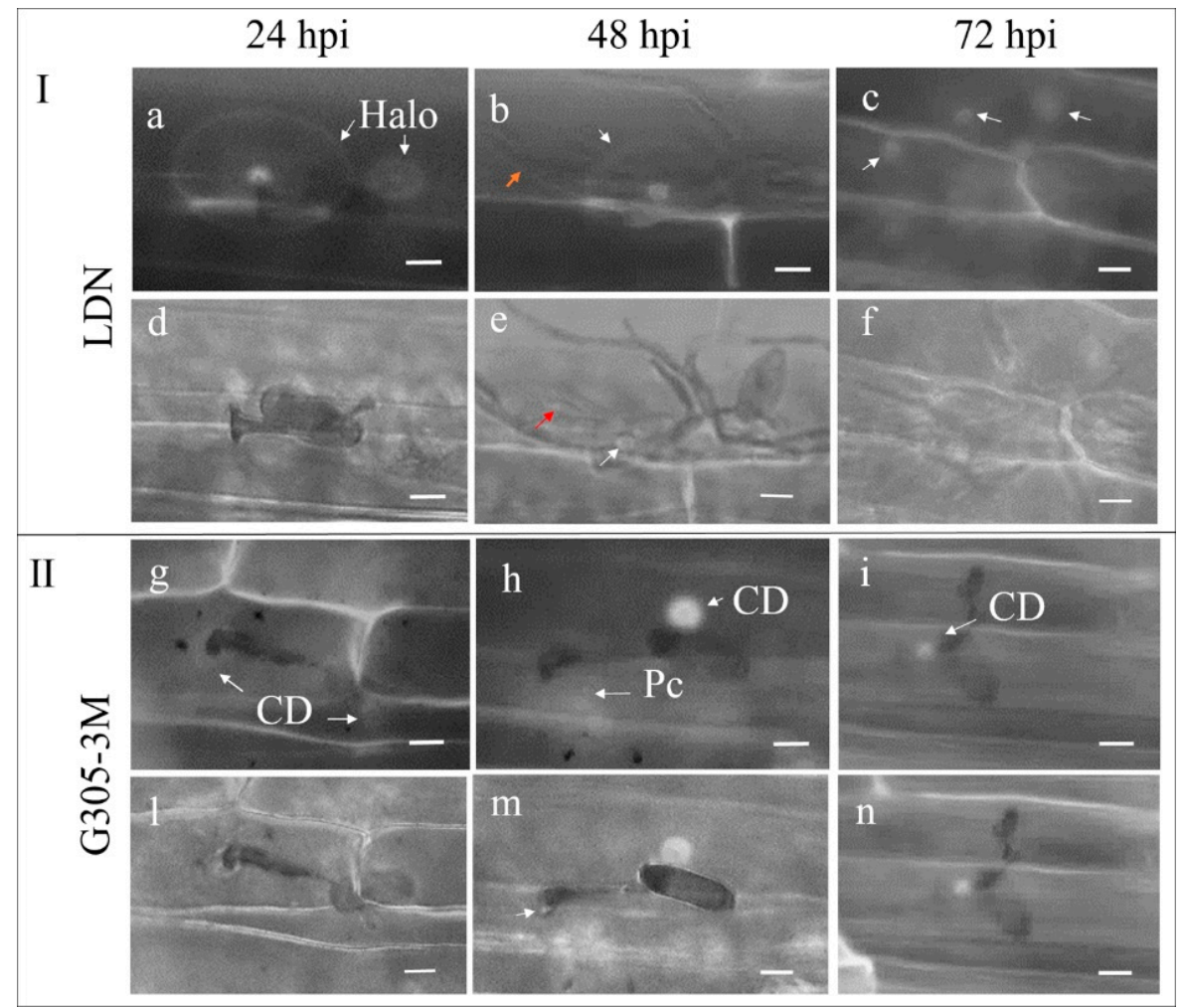

Figure 6. Fluorescence microscopy observation of callose deposition in young leaves of resistant G305-3M and susceptible LDN at 24, 48 and $72 \mathrm{hpi}$ after Bgt\#70 inoculation. In both panels, G305-3M and LDN, the upper micrographs $(\mathbf{a}-\mathbf{c}, \mathbf{g}-\mathbf{i})$ were obtained under fluorescence microscopy after aniline blue staining, while the lower micrographs $(\mathbf{d}-\mathbf{f}, \mathbf{l}-\mathbf{n})$ show callose deposition observed after superimposition of fluorescence and bright field microscope images of inoculated leaf samples stained with aniline blue. CD: callose deposition; Pc: patch-like callose deposition. Scale bar is $50 \mu \mathrm{m}$.

2.5.2. $\mathrm{H}_{2} \mathrm{O}_{2}$ Accumulation and Plant Cell Death in Epidermal Cells in Response to Bgt Inoculation

$\mathrm{H}_{2} \mathrm{O}_{2}$ accumulation was monitored during the penetration stages of $B g t$ hyphae into epidermis plant cells (1-3 dpi, Supplementary Figure S4). In the susceptible LDN, most Bgt conidia developed well with the elongated hyphae with no $\mathrm{H}_{2} \mathrm{O}_{2}$ accumulation at $2 \mathrm{dpi}$ (Figure 7a). However, a few $B g t$ conidia (1.2\% of germinated spores) had some $\mathrm{H}_{2} \mathrm{O}_{2}$ accumulation within the penetrated plant cells, as indicated by dark-brown staining from DAB polymerization (Figure $7 \mathrm{~b}, \mathrm{c}, \mathrm{i}$ ). In these rare cases, papillae (white arrow) could be observed in the same epidermal cell, but neither a haustorium nor secondary hypha were formed (Figure $7 \mathrm{~b}, \mathrm{c}$ ). In the resistant $\mathrm{G} 305-3 \mathrm{M}, 10.2 \%$ of the germinated $\mathrm{Bgt}$ conidia showed substantial accumulation of $\mathrm{H}_{2} \mathrm{O}_{2}$ in the penetrated epidermal cells and cell walls (Figure 7i). As shown in Figure 7d, the penetration of a host cell by a single Bgt conidium resulted in the accumulation of high amount of $\mathrm{H}_{2} \mathrm{O}_{2}$ within a single host cell. In some cases, when the $B g t$ penetration occurred close to the border between two neighboring epidermal cells, both showed high accumulation of $\mathrm{H}_{2} \mathrm{O}_{2}$ (Figure 7e). We also observed a small amount of $\mathrm{H}_{2} \mathrm{O}_{2}$ accumulation, which looks like a brownish hallo, occurring at the attack site of the primary germ tube of the same conidium (Figure 7e). A similar case is shown in Figure $7 \mathrm{f}$ in which a single Bgt conidium caused high $\mathrm{H}_{2} \mathrm{O}_{2}$ accumulation on two adjacent epidermal cells by forming a primary germ tube on one of them and appressorium on another. The two adjacent cells were surrounded by alive epidermal cells, which showed no accumulation of $\mathrm{H}_{2} \mathrm{O}_{2}$. Moreover, neither papillae nor digitated haustorium were seen in these invaded cells. In most cases, Bgt developed normally in the susceptible LDN and the infected cells were not stained with trypan blue indicating that they are indeed alive (Figure $7 \mathrm{~g}$ ). In contrast, in most cases, the Bgt invaded host cell of the resistant line G305-3M were stained with 
trypan blue, indicating that these cells were dead, likely as a result of induced programed cell death (Figure $7 \mathrm{~h}$ ).

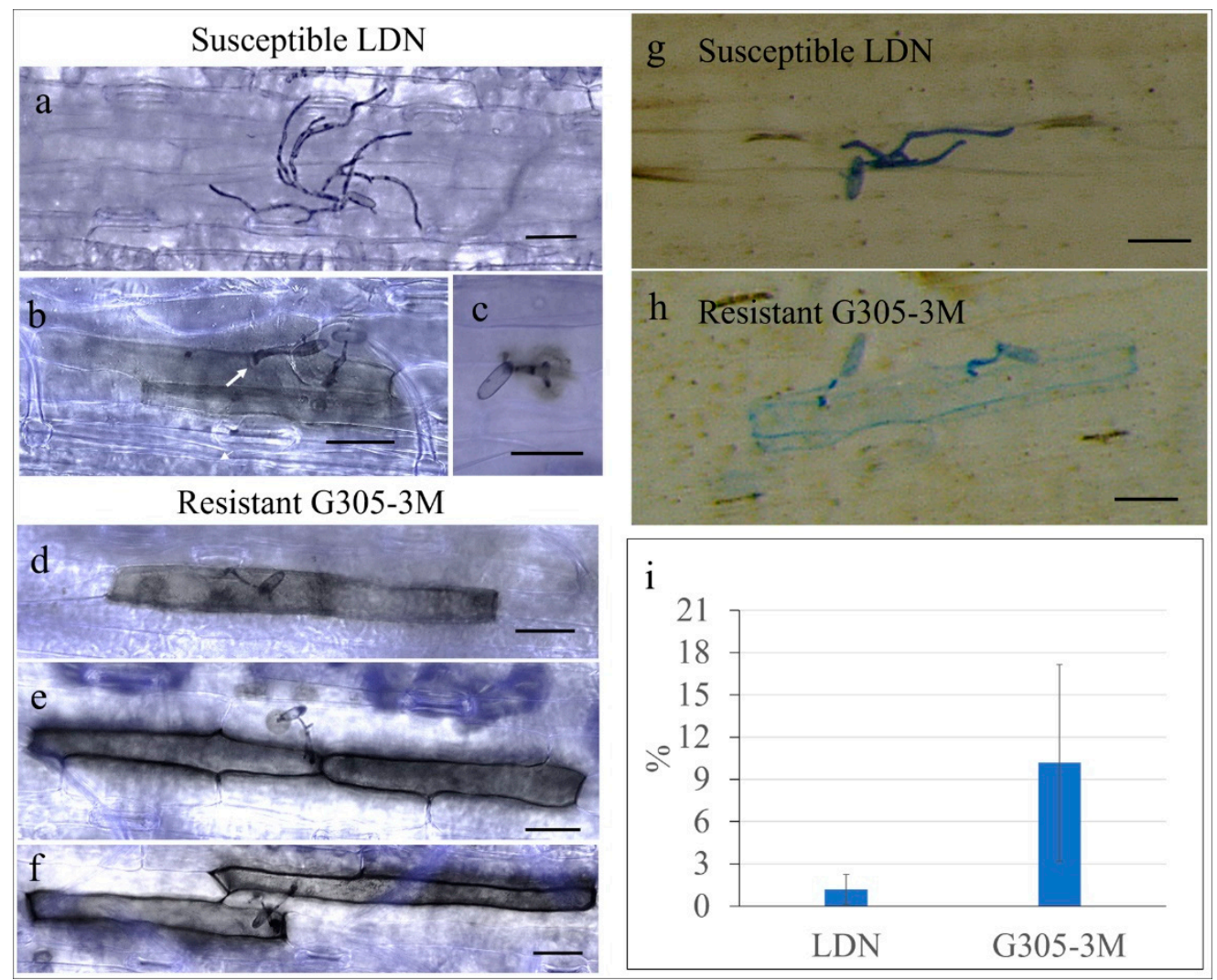

Figure 7. $\mathrm{H}_{2} \mathrm{O}_{2}$ accumulation and programmed cell death in young leaves of resistant G305-3M and susceptible LDN at 2 dpi inoculated with Bgt\#70. The leaf samples in (a-f) were stained with DAB-aniline blue, while those in $(\mathbf{g}, \mathbf{h})$ were stained with trypan blue. All micrographs were observed under a light microscope; (a-c) $\mathrm{H}_{2} \mathrm{O}_{2}$ accumulation and epidermal cell response of susceptible LDN leaves upon $\mathrm{Bg}$ t penetration; (d-f) $\mathrm{H}_{2} \mathrm{O}_{2}$ accumulated in the epidermal cells of resistant G305-3M leaves upon $B g t$ penetration. Scale bar is $50 \mu \mathrm{m}$. (i) The percentage of germinated Bgt conidia which showed $\mathrm{H}_{2} \mathrm{O}_{2}$ accumulation in the resistant G305-3M and susceptible LDN leaf segments. Error bars denote standard deviation based on nine biologic repeats.

\section{Discussion}

During the last two decades, advanced technologies that allow researchers to explore various aspects of host-pathogen interactions at the cellular and molecular levels were developed and used to clone novel plant disease resistance genes and discover their roles in the defense response against pathogens (e.g., $[14,15])$. Pathogen effector proteins were also studied extensively to expound upon resistance-effector interactions and plant NLR-triggered immunity (e.g., [16,17]), as well as the involvement of plant hormones and ROS signaling in plant defense mechanisms (e.g., $[8,18])$. Nevertheless, microscopic observations throughout the infection process remain the classical approach to study the histopathology of defense responses in host-pathogen interactions, as we used here for histological characterization of the PmG3M-mediated resistance to wheat powdery mildew.

In the current study, we used wheat germ agglutinin staining and advanced fluorescence microscopy imaging technologies to study the penetration process of germinating Bgt spores into wheat epidermal cells and the development of fungal feeding structures within the cells of a susceptible host during the asexual life cycle of Bgt. Our results confirmed previous reports stating that the asexual life cycle of powdery mildew proceeds in a strictly programmed manner and is highly synchronous [5]. Pre-penetration of conidia occurred upon landing on the host surface, indicated by the formation of a 
short aseptate primary germ tube, whose functions are to rapidly attach the fungal germling to the host surface, gain access to host water during pre-penetration and recognize characteristics of the contact surface [5]. Our results corroborate the report of Jankovics et al. [6], showing that more than one primary germ tube can germinate from a single conidium, and those primary germ tubes are distributed randomly along the conidium without uniform rules. The fully developed haustoria with numerous finger-like digitate processes were formed to increase the contact surface area with host cells in order to increase the absorption of host nutrients during the invasion stage. Subsequently, well-developed colonies were established on the susceptible host.

$B g h$ infection was previously shown to impair stomatal behavior in both susceptible and resistant barley genotypes after penetration of the pathogen into stomata neighboring cells [19]. However, this disruption was associated with the interaction with epidermis host cells and was not attributed to penetration into stomata guard cells. In the current study, we show evidence that Bgt appressoria tend to avoid penetration into stomata guard cells (Supplementary Figure S2), a finding supported by Prat et al. [19]. Therefore, we assume that powdery mildew fungi are recognizing and specifically targeting epidermal plant cells, rather than stomata guard cells. However, confirmation of such assumptions requires further experimentation which is beyond the scope of current study.

The current histopathology study is part of a long-term project aiming to clone and characterize powdery mildew and stripe rust resistance genes derived from wild emmer wheat by using the map-based cloning approach, as we recently demonstrated for the cloning of $Y r 15$ [14,20]. Previously, we localized PmG3M to chromosome 6B using the G305-3M $\times$ LDN mapping population [12]. To confirm the single-dominant gene inheritance of resistance in $P m G 3 M$, we tested the segregation ratio in G305-3M $\times$ LDN mapping population ( $265 \mathrm{~F}_{2}$ plants) and showed that only one resistance gene is segregating there (3R:1S). In addition, we have selected to identify two RILs that represent reciprocal-like recombination events between marker stm583 and $P m G 3 M$, and therefore carry alternative parental alleles of PmG3M. The homozygous resistant (CHR36) and homozygote susceptible (CHR32) RILs expressed resistance/susceptibility responses as their parents, therefore validating that the resistance response is mediated by $P m G 3 M$.

Furthermore, we demonstrated that the Bgt asexual life cycle was completed on leaves of LDN and CHR32, but not on G305-3M and CHR36. In the resistant lines, the penetration process, haustorium development and further colonization of host cells were stopped at the haustorium primordia stage. In only a few cases digitate processes could be observed, leading to the formation of short secondary hyphae, while in most cases bulb-like haustoria without any typical finger-like lobes were formed, as a result of the PmG3M-mediated resistance mechanism. Numerous studies have demonstrated that mature haustoria are crucial for successful infection and colonization of host tissue by biotroph pathogen, since they allow absorption of nutrients from the host cells and delivery of a remarkable diversity of fungal effectors that manipulate host immunity and metabolism [21,22]. In Bgh alone, almost 500 genes encoding for candidate secreted effector proteins (CSEPs) were identified and a large part of them showed a significantly higher relative expression in haustorial tissue, than the epiphytic tissue [23]. Moreover, most CSEPs (79\%) in Bgh genome are preferentially expressed in haustoria, which may indicate that they have specific functions in biotrophic pathogenesis [24]. Nevertheless, fungal effectors also play an important role in incompatible interactions by activating the resistance mechanism of host plants that carry specific receptors and recognize these effectors in a gene-for-gene manner (e.g., [25]). The AvrPm3-Pm3 effector-NLR interactions were shown to control both race-specific resistance and host-specificity of cereal mildews on wheat [26]. Therefore, the wheat-Bgt pathosystem is providing an excellent example for avirulence factors that are highly expressed at the stage of haustorium formation and recognized by $P m$ resistance genes, therefore demonstrating the importance of haustorial formation for the plant-pathogen interactions [16]. In the case of PmG3M further work is under way to clone the gene and identify its role in activating the resistance response.

Based on the accumulated results obtained using different genetic backgrounds, we can clearly demonstrate that the powdery mildew resistance mediated by PmG3M includes a post-haustorial 
resistance mechanism, which leads to the arrest of the fungal feeding structures and cessation of fungal colony growth on the leaf surface due to lack of nutrients. This resistance mechanism is different from the mlo powdery mildew resistance gene [27], which effectively arrest fungal pathogenesis at very early stages of infection prior to formation of haustoria and secondary hyphae (a pre-haustorial resistance mechanism). Although, Bgh spores make an attempt to penetrate epidermal host cells, they fail-and thus the primary formation of haustorium is prevented, sporulation does not happen and the pathogen cannot finalize its asexual life cycle $[27,28]$. Recent studies have demonstrated that mlo-mediated resistance can be effectively induced in broad range of monocotyledonous and dicotyledonous plant species, including wheat [28]. Similarly, during melon-powdery mildew (Podosphaera fusca) interactions, the $P$. fusca hyphae developed abundantly in the susceptible cultivar 'Rochet' with a large number of haustorial formations, while fungal growth is arrested at the first germ tube stage, prior to haustoria formation in the resistant line 'PMR-6' [29]. In the compatible and incompatible Arabidopsis-powdery mildew interactions, haustoria formation was prevented in resistant transgenic lines during both types of powdery mildew inoculation (Golovinomyces cichoracearum and Bgh), but developed well in susceptible lines [30]. Furthermore, the powdery mildew resistance gene Mla activated post-haustoria resistance mechanism that restricted B. graminis growth [31]. Although the directions and purposes of various host-powdery mildew studies were different, they all demonstrate that preventing haustoria formation is a conserved mechanism to arrest fungal growth and to control disease development.

Callose-containing cell-wall appositions are effective barriers that are induced at the sites of attack during the relatively early stages of pathogen invasion. However, previous studies on the function of callose deposition in host-pathogen interactions have been controversial. The work by Consonni et al. [32] demonstrated that callose deposition was irrelevant for plant resistance to adapted biotrophic powdery mildews. In contrast, Ellinger et al. [30] found that penetration resistance was important to the resistance response when callose was deposited early during the infection process and that inhibition of callose deposition was correlated with increased susceptibility of Arabidopsis to fungal pathogens [33]. Chowdhury et al. [34] then provided evidence that callose deposition positively contributes to the barley fungal penetration resistance mechanism against $B g h$. Previous reports have demonstrated that callose deposition is part of the basal defense responses of plant immunity against pathogens typically triggered by conserved pathogen-associated molecular patterns (PAMPs) (reviewed by Claverie et al. [35]). In our study, we have shown that callose deposition occurred at the fungal penetration sites, in both the resistant (G305-3M) and susceptible (LDN) genotypes, suggesting that although some basal defense responses were activated, they were not effective against virulent $B g t$, which successfully penetrated into host cells of both genotypes. Fungal development was arrested only in G305-3M and CHR36 by a post-haustorial resistance mechanism mediated by PmG3M.

Powdery mildew is an obligate parasite which can successfully grow and multiply only on living host plant cells and therefore, programmed cell death is a major component of the resistance response against this destructive disease (reviewed by Liu et al. [36]). Hydrogen peroxide $\left(\mathrm{H}_{2} \mathrm{O}_{2}\right)$ accumulation and cell death were shown to be induced after inoculation with $B g t$ spores in resistant wheat lines that harbor Pm60 [37]. In the current study, epidermal cells and cell walls of G305-3M showed strong $\mathrm{H}_{2} \mathrm{O}_{2}$ accumulation after $\mathrm{Bg}$ t inoculation, likely leading to programmed cell death of the infected epidermal cells, as evident from staining of the Bgt-penetrated cells with trypan-blue, a dye that is used for measuring cell viability. Moreover, $\mathrm{H}_{2} \mathrm{O}_{2}$ accumulation could sometimes be observed in two adjacent epidermal cells, infected by a single conidium, and it seems that both the partial penetration of one epidermal cell during attachment of the Bgt conidium via the primary germ tube and the full penetration of the second host cell via the formed appressorium, penetration peg and premature haustorium resulted in $\mathrm{H}_{2} \mathrm{O}_{2}$ accumulation. The relatively low percentage of infected epidermal cells that showed extensive $\mathrm{H}_{2} \mathrm{O}_{2}$ accumulation can be explained by the instability of ROS and timing of staining. As noted by Mittler [38], $\mathrm{H}_{2} \mathrm{O}_{2}$ accumulation is a dynamic process, and $\mathrm{H}_{2} \mathrm{O}_{2}$ can be degraded very fast, because ROS scavenging mechanisms are usually induced rapidly [38]. The trypan blue staining of infected G305-3M epidermal cells indicates that they are not viable [39], probably due 
to programed cell death induced by PmG3M. In contrast, LDN infected cells did not stain with trypan blue, indicating that they are alive. These results demonstrate that the notable defense responses, such as $\mathrm{H}_{2} \mathrm{O}_{2}$ accumulation and programmed cell death in epidermal cells play important role in the PmG3M-mediated wide-spectrum resistance.

Our results also showed that CHR32 had significantly higher accumulation of fungal biomass than the parental line LDN from 5 dpi to 10 dpi. Together with slight $\mathrm{H}_{2} \mathrm{O}_{2}$ accumulation in Bgt infected LDN, it may suggest that some partial resistance mechanisms are defending against powdery mildew in LDN background. Ben-David et al. [40] provided evidence that LDN possessed resistance responses to some of the tested $B g t$ isolates and LDN contributed to four isolate-specific quantitative resistance loci to improved powdery mildew quantitative resistance to Bgt (lower density of fungal colonies on the leaves). However, it seems that some susceptible RILs (e.g., CHR32) lost some of the defense responses harbored by LDN, leaving them even more susceptible to powdery mildew, as a result of transgressive segregation.

In summary, we have shown that haustoria were abnormally shaped in the resistant G305-3M leaves, accompanied by a series of epidermal cell reactions that apparently suppressed the multiplication and colonization of the fungus, including callose deposition, $\mathrm{H}_{2} \mathrm{O}_{2}$ accumulation, hypersensitive response and programmed cell death. A post-haustorial resistance mechanism was also observed that arrested the development of fungal feeding structures and protected the epidermal cells from an extensive fungal invasion. Further work is underway aiming to clone PmG3M and elucidate the molecular mechanism of resistance conferred by this gene. This will open the door to developing novel strategies for engineering enhanced protection against powdery mildew pathogens.

\section{Materials and Methods}

\subsection{Plant Materials and Bgt Isolate}

The WEW accession G305-3M, donor of PmG3M, and T. durum cv. LDN parental lines were used to produce homozygous $\mathrm{F}_{6}$ recombinant inbred line (RIL) population by the single seed decent procedure, as previously described [11,12]. In the current study, we used one resistant RIL (CHR36) and one susceptible RIL (CHR32), derived from the same cross that carried alternative chromosome segments with alternative alleles of PmG3M (Supplementary Table S1). The recombination events carried by these RILs in the PmG3M chromosome region were validated by molecular markers stm583 and edm149 ([11]; Supplementary Tables S1 and S2). Furthermore, we have generated an additional population $(\mathrm{G} 305-3 \mathrm{M} \times \mathrm{LDN})$ of $265 \mathrm{~F}_{2}$ plants and phenotyped them to validate the presence of a single $P m$ resistance gene (Supplementary Table S3).

Bgt isolate \#70, used in the current study, is highly virulent on many known powdery mildew resistance genes (e.g., Pm1a, Pm1b, Pm2, Pm3a, Pm3b, Pm3c, Pm3d, Pm5a, Pm5b, Pm6, Pm7, Pm17, Pm22 and $P m 1+P m 2+P m 9 ;[41])$. G305-3M and CHR36 are highly resistant to infection with Bgt isolate \#70 $(\mathrm{IT}=0)$, while LDN and CHR32 are susceptible $(\mathrm{IT}=4)[11,12]$.

\subsection{Bgt Infection and Disease Assessment}

All plant materials were tested at the two-leaf stage and the results were recorded at 7 and $10 \mathrm{dpi}$. Conditions of inoculation, incubation and disease assessment were as described by Hsam \& Zeller [42]. In brief, the first leaf of each plant at the seedling stage was cut into three segments and cultured on $8 \mathrm{~g} / \mathrm{L}$ agar containing $50 \mathrm{mg} / \mathrm{L}$ benzimidazole (Sigma-Aldrich, St. Louis, MO, USA) in square petri dishes. After even inoculation with powdery mildew fresh spores, the samples were incubated at $20-22{ }^{\circ} \mathrm{C}$ with a 16 -hour photoperiod. The reactions to $B g t$ inoculation were examined visually, with the infection type (IT) recorded based on a scale of 0 to 4 [12]. 


\subsection{Microscopic Observations of Wheat-Bgt Interactions within Infected Leaves}

Fluorescence microscopy of $B g t$ structures was performed using wheat germ agglutinin (WGA; a lectin that binds specifically to $\beta(1 \rightarrow 4)-\mathrm{N}$-acetyl-D-glucosamine, i.e., chitin) conjugated with a fluorescent dye, according to Dawson et al. [43] and Klymiuk et al. [14,20], with slight modifications. Leaf segments (primary leaf, $5 \mathrm{~cm}$ long) were sampled at 4, 8, 12, 18, 24, 32, 48, 72, 96, 120, 144, 168 and $240 \mathrm{~h}$ post inoculation (hpi) with Bgt spores. Harvested leaf segments were incubated in $1 \mathrm{M} \mathrm{KOH}$ at $37^{\circ} \mathrm{C}$ for $24 \mathrm{~h}$, neutralized in $50 \mathrm{mM}$ Tris, $\mathrm{pH} 7.0$, stained with $20 \mu \mathrm{g} / \mathrm{mL}$ solution of WGA conjugated to fluorophore Alexa 488 (L4895-2MG; Sigma-Aldrich), then washed and mounted on microscope slides with fluorescence antifade mounting medium (Vectashield, Vector Laboratories, Burlingame, CA, USA), covered and sealed with cover glass. The sealed samples can be stored at $4{ }^{\circ} \mathrm{C}$ in the dark over a month. An inverted fluorescence microscope, Leica DMi8 (Leica Microsystems, Wetzlar, Germany), fitted with a filter cube for the FITC excitation range (Ex: 460-500; Dc: 505; Em: 512-542) and a FLUO regime, was used to observe the WGA-stained fungal structures.

Fluorescence microscopy of callose deposition was performed using aniline blue (Sigma-Aldrich) to demonstrate the presence of $\beta$-1,3-glucan in the plant cell walls penetrated by the fungal pathogen, according to Lyngkjær \& Carver [44]. In brief, the leaf segments (primary leaf, $5 \mathrm{~cm}$ long) were placed, with the inoculated surfaces up, onto Whatman \#1 paper moistened with ethanol and acetic acid (3:1, v/v) until completely bleached (approximately 16-20 h). Then the samples were transferred to filter paper moistened with the clearing solution lactoglycerol (lactic acid: glycerol: water $(1: 1: 1, v / v / v))$ for $3 \mathrm{~h}$. Finally, fungal structures were stained for $30 \mathrm{~min}$ by carefully pipetting a few droplets of $0.05 \%(w / v)$ aniline blue in acetic acid: glycerol: water $(1: 1: 1, v / v / v)$ onto the inoculated surface. The fluorescence microscopy was performed on an inverted fluorescence microscope, Leica DMi8 using the 4',6-diamidino-2-phenylindole (DAPI) filter set (Ex: $325-375 \mathrm{~nm}$; Em: $435-485 \mathrm{~nm}$ ). During our microscopic observations, we could observe obvious dot-like callose deposition within blue backgrounds. However, in order to improve the contrast between callose depositions and background, we have changed the color saturation in the presented images.

To visualize hydrogen peroxide $\left(\mathrm{H}_{2} \mathrm{O}_{2}\right)$ accumulation, 3,3'-diaminobenzidine (DAB) staining was performed on leaf segments inoculated with Bgt as described by Thordal-Christensen et al. [45].

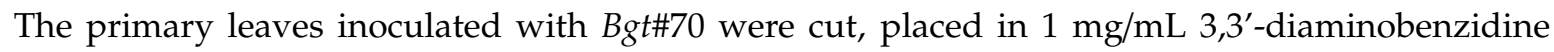
(DAB)- $\mathrm{HCl}$ at $\mathrm{pH} 3.8$ (as a low $\mathrm{pH}$ is necessary to solubilize $\mathrm{DAB}$ ) and incubated at $20^{\circ} \mathrm{C}$ for $8 \mathrm{~h}$ prior to sampling. The leaf segments were then cleared in boiling ethanol (96\%) for $15 \mathrm{~min} . \mathrm{H}_{2} \mathrm{O}_{2}$ is visualized as a reddish-brown coloration using fluorescence microscope with a DAPI filter. For DAB observation, the images were recorded after superimposition of bright field and fluorescence after aniline blue-DAB staining. In our preliminary testing of $\mathrm{H}_{2} \mathrm{O}_{2}$ accumulation (Supplementary Figure $\mathrm{S} 4$ ), we could observe clear $\mathrm{H}_{2} \mathrm{O}_{2}$ accumulation in plant cells of G305-3M at 2 and 3 dpi. In previous studies it was shown that $\mathrm{H}_{2} \mathrm{O}_{2}$ accumulation was detected at 2 dpi [37]. Therefore, we have selected $2 \mathrm{dpi}$ for a more detailed examination (Figure 7).

Since trypan blue stains dead plant cells and fungal hyphae [39], we used it to observe plant cell death after Bgt inoculation. This experiment was performed with inoculated samples at $2 \mathrm{dpi}$ via a similar procedure as in the observation of callose deposition. After trypan blue (Sigma-Aldrich) staining, the samples were observed under a light microscope (Nikon, AZ100, Tokyo Met., Japan).

All microscopic observation experiments were repeated 2-3 times, with at least three biologic replicates each time.

\subsection{Quantification of Fungal Biomass within Infected Leaves}

The quantification of fungal biomass was based on the estimation of chitin content using chitin binding WGA conjugated to fluorophore fluorescent dye as described by Ayliffe et al. [46] and Klymiuk et al. [14] with slight modifications. After inoculation with Bgt isolate \#70, leaf segments of the two parental lines (G305-3M and LDN) and the two RILs (CHR36 and CHR32), were collected 1-7 dpi and $10 \mathrm{dpi}$ from different plants at each time point. Five biologic replicates were collected from 
each line at each time point and used for quantification of fungal biomass by chitin measurement. Leaf segments were weighed, cut into 3-4 cm pieces, placed in 15-mL Falcon tubes and covered with 5-6 mL of $1 \mathrm{M} \mathrm{KOH}$ containing 2-3 drops of the surfactant alkylaryl polyether alcohol (Spreader DX). Plant materials were autoclaved using a standard sterilization cycle $\left(121^{\circ} \mathrm{C}\right.$ and 15 psi for $\left.20 \mathrm{~min}\right)$ followed by quick washing with $15 \mathrm{~mL}$ of $50 \mathrm{mM}$ Tris $\mathrm{HCl}, \mathrm{pH} 7.0$ and neutralization by a second wash with $15 \mathrm{~mL}$ of $50 \mathrm{mM}$ Tris $\mathrm{HCl}, \mathrm{pH} 7.0$ for at least $15 \mathrm{~min}$. Centrifugation for $5 \mathrm{~min}$ at $4700 \times g$, was used during all steps to avoid losing fungal materials. To avoid destroying the fragile leaf tissues, the leaf segments were gently moved to a new falcon tube, then the remaining solution was spun down the fungal materials were collected at the bottom. Neutralized tissues and spun down materials were carefully transferred to $1.7 \mathrm{~mL}$ microcentrifuge tubes that contained $1 \mathrm{~mL}$ of $50 \mathrm{mM}$ Tris $\mathrm{HCl}, \mathrm{pH} 7.0$ for each $200 \mathrm{mg}$ of fresh leaf tissue, according to measurements conducted at harvest time. Leaf samples were then homogenized at $30 \mathrm{~Hz}$ for $2 \mathrm{~min}$ in a TissueLyser II (Qiagenza) and a $100 \mu \mathrm{L}$ aliquot of each sample suspension was transferred to a $200-\mu \mathrm{L}$ microcentrifuge tube that contained $10 \mu \mathrm{L}$ of a $0.5 \mathrm{mg} / \mathrm{mL}$ solution of WGA conjugated to fluorophore Alexa 488 dissolved in water. Three technical replicates were used for each tissue sample. The ends of pipette tips were removed prior to all sample pipetting and homogenates were regularly agitated to ensure that a uniform sample was collected. The sample and stain solution were well mixed by repetitive pipetting and left to stand for $30 \mathrm{~min}$ at room temperature. Following staining, samples were centrifuged at $600 \times g$ for $3 \mathrm{~min}$. The supernatant containing unbound stain was removed by pipetting and the pellet was resuspended in $200 \mu \mathrm{L}$ of $50 \mathrm{mM}$ Tris, $\mathrm{pH}$ 7.0. Samples were washed six times in $200 \mu \mathrm{L}$ of $50 \mathrm{mM}$ Tris (pH 7.0), resuspended in $100 \mu \mathrm{L}$ of $50 \mathrm{mM}$ Tris (pH 7.0) and transferred to black, 96-well microtiter trays for fluorometry. Fluorometric measurements were conducted using a SpectraMax M2e Microplate Reader (Molecular Devices, Sunnyvale, CA, USA) set with 485-nm excitation and 535-nm emission wavelengths, a $1.0 \mathrm{~s}$ measurement time and a cross pattern of well-scanning, yielding an average measurement per well.

In addition, to optimize the protocol for measurement of fungal biomass, the background fluorescence from the host plant was documented and taken into account when performing the measurements (Supplementary Figure S5).

\subsection{Statistical Analysis}

Chi-squared distribution analysis was carried out to determine the segregation ratio of $B g t$ phenotype responses of $\mathrm{F}_{2}$ plants from the G305-3M $\times$ LDN mapping population. The percentage of germinated $\mathrm{Bgt}$ conidia which resulted in $\mathrm{H}_{2} \mathrm{O}_{2}$ accumulation in the resistant G305-3M and susceptible LDN leaf segments were analyzed through SPSS (SPSS 16.0, SPSS, Inc; Chicago, IL, USA).

Statistical analyses of the accumulation of fungal biomass were determined by the following linearized formula to identify the logistic fungal growth model [47]:

$$
\ln [y /(K-y)]=\ln \left[y_{0} /\left(K-y_{0}\right)\right]+r_{L} \cdot t
$$

$K(=K \max )=$ maximum level of disease $(y)$ or asymptote of disease progress curve, $y=$ disease at time of observation, $y_{0}=$ level of disease at first observation, $r_{L}=$ rate of disease increase for the specific model and $t=$ time interval being considered.

One-way analysis of variance (ANOVA) was also carried out to analyze the accumulation of fungal biomass using Duncan's multiple range test through SPSS (SPSS 16.0, SPSS, Inc). Significant effects were set at $p<0.01$. Data were checked for normality and the homogeneity of variances during the analysis.

Supplementary Materials: The following are available online at http://www.mdpi.com/2076-0817/9/6/418/s1, Figure S1: Bgt development in resistant RIL CHR36 and susceptible RIL CHR32 at 4 and 10 dpi. Figure S2: Bgt penetration and haustoria formation in both resistant G305-3M and susceptible LDN, avoiding stomatal guard cell. Figure S3: The comparison of fungal biomass between the susceptible (CHR32 and LDN) and resistant (CHR36 and G305-3M) lines at the same time frame. Figure S4: Pretesting of $\mathrm{H}_{2} \mathrm{O}_{2}$ accumulation in young leaves of resistant G305-3M and susceptible LDN at 1 to 3 dpi inoculated with Bgt\#70. Figure S5: Optimization of wheat 
germ agglutinin (WGA) chitin (WAC) fungal biomass measurement method and comparative amounts of fungal biomass accumulation within leaf tissues resistant RIL CHR36 and susceptible RIL CHR32. Table S1: Graphical genotypes of $\mathrm{F}_{6}$ recombinant inbred lines (RILs) derived from the cross of T. dicoccoides accession G305-3M with T. durum cultivar LDN. Table S2: A list of the publicly available markers, used in the current study, their locus name, type, primer sequence and fragment length in Triticum durum cv LDN and Triticum dicoccoides G305-3M. Table S3: Segregation ratio of the response to infection with isolate $B g t \# 70 \mathrm{~F}_{2}$ in the progenies of the cross between the susceptible LDN and the resistant G305-3M, used for genetic mapping for PmG3M.

Author Contributions: Conceived and designed the study, T.F. and Z.-Z.W.; developed the WGA staining method and contributed to experimental design, V.K.; identified the RILs, V.B. and Z.-Z.W.; carried out the PmG3M verification, disease assessment, microscopic observations, fungal biomass measurement and plant cell responses to Bgt, first draft preparation, Z.-Z.W.; writing, reviewing and editing, Z.-Z.W., T.F., V.K. and C.P.; coordination and funding acquisition, T.F. All authors have read and agreed to the published version of the manuscript.

Funding: This study was supported by the Israel Science Foundation, Grant Number 1719/08 and 1366/18.

Acknowledgments: Z.W. was supported by the China Scholarship Council for financial support and the University of Haifa Graduate School. Many thanks to Tamar Kis-Papo for her technical support.

Conflicts of Interest: The authors declare no conflict of interest.

\section{References}

1. Glawe, D.A. The powdery mildews: A review of the world's most familiar (yet poorly known) plant pathogens. Phytopathology 2008, 46, 27-51. [CrossRef]

2. Braun, U.; Cook, R.T.A.; Inman, A.J.; Shin, H.D.; Bélanger, R.R.; Bushnell, W.R.; Dik, A.J.; Carver, T.L.W. The taxonomy of the powdery mildew fungi. In The Powdery Mildews: A Comprehensive Treatise; APS Press: St. Paul, MN, USA, 2002; pp. 13-55.

3. Twamley, A.; Gaffney, M.; Feechan, A. A microbial fermentation mixture primes for resistance against powdery mildew in wheat. Front. Plant Sci. 2019, 10, 1241. [CrossRef]

4. Inuma, T.; Khodaparast, S.A.; Takamatsu, S. Multilocus phylogenetic analyses within Blumeria graminis, a powdery mildew fungus of cereals. Mol. Phylogenet. Evol. 2007, 44, 741-751. [CrossRef] [PubMed]

5. Both, M.; Csukai, M.; Stumpf, M.P.H.; Spanu, P.D. Gene expression profiles of Blumeria graminis indicate dynamic changes to primary metabolism during development of an obligate biotrophic pathogen. Plant Cell 2005, 17, 2107-2122. [CrossRef]

6. Jankovics, T.; Komáromi, J.; Fábián, A.; Jäger, K.; Vida, G.; Kiss, L. New insights into the life cycle of the wheat powdery mildew: Direct observation of ascosporic infection in Blumeria graminis f. sp. tritici. Phytopathology 2015, 105, 797-804. [CrossRef]

7. Chowdhury, J.; Henderson, M.; Schweizer, P.; Burton, R.A.; Fincher, G.B.; Little, A. Differential accumulation of callose, arabinoxylan and cellulose in nonpenetrated versus penetrated papillae on leaves of barley infected with Blumeria graminis f. sp. hordei. New Phytol. 2014, 204, 650-660. [CrossRef] [PubMed]

8. Hückelhoven, R. Cell wall-associated mechanisms of disease resistance and susceptibility. Annu. Rev. Phytopathol. 2007, 45, 101-127. [CrossRef]

9. Li, A.L.; Wang, M.L.; Zhou, R.H.; Kong, X.Y.; Huo, N.X.; Wang, W.S.; Jia, J.Z. Comparative analysis of early $\mathrm{H}_{2} \mathrm{O}_{2}$ accumulation in compatible and incompatible wheat-powdery mildew interactions. Plant Pathol. 2005, 54, 308-316. [CrossRef]

10. Gerechter-Amitai, Z.K.; Grama, A.; Kleitman, F.; Daos, A. Improvement of Cultivated Wheat by Transfer of High Protein Potential and Resistance to Powdery Mildew and Yellow Rust from Wild Emmer Wheat; A Final Report; The Netherlands Ministry of Development Cooperation: Hague, The Netherlands, 1992.

11. Ben-David, R. Molecular Mapping of Powdery Mildew Resistance Genes Derived from the Triticum turgidum Gene Pool. Ph.D. Thesis, University of Haifa, Haifa, Israel, 2011.

12. Xie, W.; Ben-David, R.; Zeng, B.; Distelfeld, A.; Röder, M.S.; Dinoor, A.; Fahima, T. Identification and characterization of a novel powdery mildew resistance gene PmG3M derived from wild emmer wheat, Triticum dicoccoides. Theor. Appl. Genet. 2012, 124, 911-922. [CrossRef] [PubMed]

13. Hao, Y.; Parks, R.; Cowger, C.; Chen, Z.; Wang, Y.; Bland, D.; Murphy, J.P.; Guedira, M.; Brown-Guedira, G.; Johnson, J. Molecular characterization of a new powdery mildew resistance gene Pm54 in soft red winter wheat. Theor. Appl. Genet. 2015, 128, 465-476. [CrossRef] [PubMed] 
14. Klymiuk, V.; Yaniv, E.; Huang, L.; Raats, D.; Fatiukha, A.; Chen, S.; Feng, L.; Frenkel, Z.; Krugman, T.; Lidzbarsky, G.; et al. Cloning of the wheat $Y r 15$ resistance gene sheds light on the plant tandem kinase-pseudokinase family. Nat. Commun. 2018, 9, 3735. [CrossRef] [PubMed]

15. Krattinger, S.G.; Keller, B. Molecular genetics and evolution of disease resistance in cereals. New Phytol. 2016, 212, 320-332. [CrossRef] [PubMed]

16. Bourras, S.; McNally, K.E.; Ben-David, R.; Parlange, F.; Roffler, S.; Praz, C.R.; Oberhaensli, S.; Menardo, F.; Stirnweis, D.; Frenkel, Z. Multiple avirulence loci and allele-specific effector recognition control the Pm3 race-specific resistance of wheat to powdery mildew. Plant Cell 2015, 27, 2991-3012. [PubMed]

17. Lolle, S.; Stevens, D.; Coaker, G. Plant NLR-triggered immunity: From receptor activation to downstream signaling. Curr. Opin. Immunol. 2020, 62, 99-105. [CrossRef]

18. Berens, M.L.; Berry, H.M.; Mine, A.; Argueso, C.T.; Tsuda, K. Evolution of hormone signaling networks in plant defense. Annu. Rev. Phytopathol. 2017, 55, 401-425. [CrossRef]

19. Prats, E.; Gay, A.P.; Mur, L.A.J.; Thomas, B.J.; Carver, T.L.W. Stomatal lock-open, a consequence of epidermal cell death, follows transient suppression of stomatal opening in barley attacked by Blumeria graminis. J. Exp. Bot. 2006, 57, 2211-2226. [CrossRef]

20. Klymiuk, V.; Fatiukha, A.; Raats, D.; Bocharova, V.; Huang, L.; Feng, L.; Jaiwar, S.; Pozniak, C.; Coaker, G.; Dubcovsky, J.; et al. Three previously characterized resistances to yellow rust are encoded by a single locus Wtk1. J. Exp. Bot. 2020, 71, 2561-2572. [CrossRef]

21. Wang, S.; Welsh, L.; Thorpe, P.; Whisson, S.C.; Boevink, P.C.; Birch, P.R.J. The Phytophthora infestans haustorium is a site for secretion of diverse classes of infection-associated proteins. mBio 2018, 9, 1216. [CrossRef]

22. Catanzariti, A.-M.; Dodds, P.N.; Lawrence, G.J.; Ayliffe, M.A.; Ellis, J.G. Haustorially expressed secreted proteins from flax rust are highly enriched for avirulence elicitors. Plant Cell 2006, 18, 243-256. [CrossRef]

23. Pedersen, C.; Van Themaat, E.V.L.; McGuffin, L.J.; Abbott, J.C.; Burgis, T.A.; Barton, G.; Bindschedler, L.V.; Lu, X.; Maekawa, T.; Weßling, R.; et al. Structure and evolution of barley powdery mildew effector candidates. BMC Genom. 2012, 13, 694. [CrossRef]

24. Spanu, P.D.; Abbott, J.C.; Amselem, J.; Burgis, T.A.; Soanes, D.M.; Stuber, K.; Van Themaat, E.; Brown, J.K.; Butcher, S.A.; Gurr, S.J.; et al. Genome expansion and gene loss in powdery mildew fungi reveal tradeoffs in extreme parasitism. Science (80) 2010, 330, 1543-1546. [CrossRef] [PubMed]

25. Saur, I.M.; Bauer, S.; Kracher, B.; Lu, X.; Franzeskakis, L.; Müller, M.C.; Sabelleck, B.; Kümmel, F.; Panstruga, R.; Maekawa, T.; et al. Multiple pairs of allelic MLA immune receptor-powdery mildew AVRA effectors argue for a direct recognition mechanism. eLife 2019, 8. [CrossRef] [PubMed]

26. Bourras, S.; Kunz, L.; Xue, M.; Praz, C.R.; Müller, M.C.; Kälin, C.; Schläfli, M.; Ackermann, P.; Flückiger, S.; Parlange, F.; et al. The AvrPm3-Pm3 effector-NLR interactions control both race-specific resistance and host-specificity of cereal mildews on wheat. Nat. Commun. 2019, 10, 2292. [CrossRef] [PubMed]

27. Lyngkjær, M.; Newton, A.; Atzema, J.; Baker, S. The barley mlo-gene: An important powdery mildew resistance source. Agron. EDP Sci. 2000, 20, 745-756. [CrossRef]

28. Kusch, S.; Panstruga, R. mlo-based resistance: An apparently universal "weapon" to defeat powdery mildew disease. Mol. Plant Microbe Interact. 2017, 30, 179-189. [CrossRef] [PubMed]

29. Romero, D.; Rivera, M.E.; Cazorla, F.M.; Codina, J.C.; Fernández-Ortuño, D.; Torés, J.A.; Pérez-García, A.; De Vicente, A. Comparative histochemical analyses of oxidative burst and cell wall reinforcement in compatible and incompatible melon-powdery mildew (Podosphaera fusca) interactions. J. Plant Physiol. 2008, 165, 1895-1905. [CrossRef] [PubMed]

30. Ellinger, D.; Naumann, M.; Falter, C.; Zwikowics, C.; Jamrow, T.; Manisseri, C.; Somerville, S.C.; Voigt, C.A. Elevated early callose deposition results in complete penetration resistance to powdery mildew in Arabidopsis. Plant Physiol. 2013, 161, 1433-1444. [CrossRef]

31. Shen, Q.-H.; Saijo, Y.; Mauch, S.; Biskup, C.; Bieri, S.; Keller, B.; Seki, H.; Ülker, B.; Somssich, I.E.; Schulze-Lefert, P. Nuclear activity of MLA immune receptors links isolate-specific and basal disease-resistance responses. Science (80) 2007, 315, 1098-1103. [CrossRef]

32. Consonni, C.; Bednarek, P.; Humphry, M.; Francocci, F.; Ferrari, S.; Harzen, A.; Van Themaat, E.V.L.; Panstruga, R. Tryptophan-derived metabolites are required for antifungal defense in the Arabidopsis mlo2 mutant. Plant Physiol. 2010, 152, 1544-1561. [CrossRef] 
33. Jacobs, A.K.; Lipka, V.; Burton, R.A.; Panstruga, R.; Strizhov, N.; Schulze-Lefert, P.; Fincher, G.B. An Arabidopsis callose synthase, GSL5, is required for wound and papillary callose formation. Plant Cell 2003, 15, 2503-2513. [CrossRef]

34. Chowdhury, J.; Schober, M.S.; Shirley, N.J.; Singh, R.R.; Jacobs, A.K.; Douchkov, D.; Schweizer, P.; Fincher, G.B.; Burton, R.A.; Little, A. Down-regulation of the glucan synthase-like 6 gene (HvGsl6) in barley leads to decreased callose accumulation and increased cell wall penetration by Blumeria graminis $\mathrm{f}$. sp. hordei. New Phytol. 2016, 212, 434-443. [CrossRef] [PubMed]

35. Claverie, J.; Balacey, S.; Lemaître-guillier, C.; Brulé, D.; Chiltz, A.; Granet, L.; Noirot, E.; Daire, X.; Darblade, B.; Héloir, M.; et al. The cell wall-derived xyloglucan is a new DAMP triggering plant immunity in Vitis vinifera and Arabidopsis thaliana. Front. Plant Sci. 2018, 9, 1725. [CrossRef] [PubMed]

36. Liu, X.; Williams, C.E.; Nemacheck, J.A.; Wang, H.; Subramanyam, S.; Zheng, C.; Chen, M.-S. Reactive oxygen species are involved in plant defense against a gall midge. Plant Physiol. 2010, 152, 985-999. [CrossRef] [PubMed]

37. Zou, S.; Wang, H.; Li, Y.; Kong, Z.; Tang, D. The NB-LRR gene Pm60 confers powdery mildew resistance in wheat. New Phytol. 2018, 218, 298-309. [CrossRef] [PubMed]

38. Mittler, R. Oxidative stress, antioxidants and stress tolerance. Trends Plant Sci. 2002, 7, 405-410. [CrossRef]

39. Van Wees, S. Phenotypic analysis of Arabidopsis mutants: Trypan blue stain for fungi, oomycetes, and dead plant cells. Cold Spring Harb. Protoc. 2008, 3, pdb-prot4982. [CrossRef] [PubMed]

40. Ben-David, R.; Peleg, Z.; Dinoor, A.; Saranga, Y.; Korol, A.B.; Fahima, T. Genetic dissection of quantitative powdery mildew resistance loci in tetraploid wheat. Mol. Breed. 2014, 34, 1647-1658. [CrossRef]

41. Ben-David, R.; Dinoor, A.; Peleg, Z.; Fahima, T. Reciprocal hosts' responses to powdery mildew isolates originating from domesticated wheats and their wild progenitor. Front. Plant Sci. 2018, 9, 75. [CrossRef]

42. Hsam, S.L.K.; Zeller, F.J. Evidence of allelism between genes Pm8 and Pm17 and chromosomal location of powdery mildew and leaf rust resistance genes in the common wheat cultivar 'Amigo'. Plant Breed. 1997, 116, 119-122. [CrossRef]

43. Dawson, A.M.; Bettgenhaeuser, J.; Gardiner, M.; Green, P.; Hernández-Pinzón, I.; Hubbard, A.; Moscou, M.J. The development of quick, robust, quantitative phenotypic assays for describing the host-nonhost landscape to stripe rust. Front. Plant Sci. 2015, 6, 876. [CrossRef]

44. Lyngkjær, M.F.; Carver, T.L.W. Induced accessibility and inaccessibility to Blumeria graminis f. sp. hordei in barley epidermal cells attacked by a compatible isolate. Physiol. Mol. Plant Pathol. 1999, 55, 151-162.

45. Thordal-Christensen, H.; Zhang, Z.; Wei, Y.; Collinge, D.B. Subcellular localization of $\mathrm{H}_{2} \mathrm{O}_{2}$ in plants. $\mathrm{H}_{2} \mathrm{O}_{2}$ accumulation in papillae and hypersensitive response during the barley-powdery mildew interaction. Plant J. 1997, 11, 1187-1194. [CrossRef]

46. Ayliffe, M.; Periyannan, S.K.; Feechan, A.; Dry, I.; Schumann, U.; Wang, M.-B.; Pryor, A.; Lagudah, E. A simple method for comparing fungal biomass in infected plant tissues. Mol. Plant Microbe Interact. 2013, 26, 658-667. [CrossRef] [PubMed]

47. Campbell, C.L. Disease progress in time: Modelling and data analysis. In The Epidemiology of Plant Diseases; Jones, D.G., Ed.; Springer: Dordrecht, The Netherlands, 1998; pp. 181-206.

(C) 2020 by the authors. Licensee MDPI, Basel, Switzerland. This article is an open access article distributed under the terms and conditions of the Creative Commons Attribution (CC BY) license (http://creativecommons.org/licenses/by/4.0/). 